\title{
INOVAÇÃO E APRENDIZAGEM PARA A CRIAÇÃO DE OPORTUNIDADES NA ASSOCIAÇÃO COMUNITÁRIA RECICLANDO PARA A VIDA
}

\author{
Nildo da Silva Dias ${ }^{1}$ \\ Helen Flávia de Lima $^{2}$ \\ Karidja Kalliany Carlos de Freitas Moura ${ }^{3}$ \\ Marcia Regina Farias da Silva ${ }^{4}$
}

\begin{abstract}
RESUMO
Os resíduos sólidos são partes de resíduos que são gerados após a produção, utilização ou transformação de bens de consumos. Todos os resíduos que não são orgânicos podem ser considerados como sendo resíduos sólidos. Muitos destes resíduos sólidos são compostosde materiais recicláveis e podem retornar a cadeia de produção, gerando renda para trabalhadores e lucro para empresas. Para que isto ocorra, é necessário que haja nas cidades um bom sistema de coleta seletiva e reciclagem de lixo. Em Mossoró-RN, a Associação Comunitária Reciclando para a Vida (ACREVI) realiza a coleta seletiva,em parceria com a prefeitura municipal, de uma parcela dos resíduossólidos produzido no município. Nesse sentido, conduziuse uma pesquisa-ação com a finalidade de contribuir para aumentar a renda e a qualidade de vida dos associados, o que nos levou a investigar, em parceria com os associados da ACREVI, os principais problemaspresentes na Associação, com vistas a identificar a necessidade de mudanças e contribuir com a transformação da realidade social dos associados. O maior desafio dessa pesquisa foi a tentativa constantede envolvimento de alguns catadores no projeto, sendo este dificultado pelo ciclo rotineiro de saída e entrada de novos associados, dificultando a participação deles em algumas decisões.
\end{abstract}

Palavras-chave: Resíduos sólidos; Sustentabilidade; Aprendizagem.

\section{INNOVATION AND LEARNING TO CREATE OPPORTUNITIES IN THECOMMUNITY ASSOCIATION RECYCLING FOR LIFE}

\footnotetext{
1 Doutor em Agronomia pela Universidade de São Paulo (USP/ESALq). É professor Associado IV da Universidade Federal Rural do Semi-Árido e Bolsista de Produtividade em Pesquisa - Nível 1 A. Lattes:http://lattes.cnpq.br/1438691490740154.

2 Mestre em história pela Universidade Estadual Paulista-Júlio de Mesquita Filho (UNESP/USP). É professora e tutora do curso de Especialização a distância em Mídias na Educação (UERN/UAB/CAPES).Lattes: http://lattes.cnpq.br/2212716262674824.

3 Doutorado em Ciências pela Universidade Federal Rural do Semi-Árido (UFERSA). É professora e coordenadora de pesquisa e extensão da Faculdade Católica do Rio Grande do Norte. Lattes: http:// lattes.cnpq.br/2911953231175843.

4 Doutora em Ecologia Aplicada pela Universidade de São Paulo - USP/ESALq. É professora Adjunta IV da Universidade do Estado do Rio Grande do Norte. Lattes: http://lattes.cnpq.br/3982283135879345.
} 
Solid waste is parts of waste that is generated after the production, use or processingof consumer goods. All waste that is not organic can be considered as solid waste. Many of these solid wastes are composed of recyclable materials and can return to theproduction chain, generating income for workers and profit for companies. For this to occur, it is necessary that there is a good system of selective collection and recycling of garbage in the cities. In Mossoró-RN, the Community Association Recycling for Life(ACREVI) performs the selective collection, in partnership with the city hall, of a portionof the solid waste produced in the municipality. In this sense, an action research wasconducted with the purpose of contributing to increase the income and quality of life ofthe associates, which led us to investigate, in partnership with acrevi associates, the main problems present in the Association, with a view to identifying the need for changeand contributing to the transformation of the social reality of the associates. The biggestchallenge of this research was the constant attempt to engage some waste pickersin the project, which is hampered by the routine cycle of departure and entry of new members, making it difficult for them to participate in some decisions.

Keywords: Solid waste; Sustainability; Apprenticeship.

\section{INTRODUÇÃO}

O gerenciamento de resíduos sólidos é provavelmente o maior problema a ser enfrentado por um gestor público. É também uma questão de saúde pública, segurança ambiental, qualidade de vida e desenvolvimento econômico. Uma cidade que não consegue gerir eficientemente os seus resíduos, raramente é capaz de gerenciar os serviços mais complexos, como saúde, educação e transporte. Várias alternativas são apontadas para evitar os impactos negativos da destinação inadequada do lixo produzido nas cidades, como, por exemplo, a coleta seletiva, os aterros sanitários e industriais, as incineradoras, a logística reversa e as usinas de compostagem.

A coleta seletiva visando à reciclagem dos resíduos sólidos urbanos é uma alternativa promissora no aspecto da sustentabilidade socioambiental, uma vez elimina os problemas dos lixões e ainda tem a vantagem extra de incluir os catadores nesta atividade lucrativa, assegurando-lhe oportunidade de trabalho e renda. Em Mossoró-RN, a Associação Comunitária Reciclando para a Vida (ACREVI) realiza a coleta seletiva, em parceria com a prefeitura municipal, de uma parcela dos resíduos sólidos produzido no município.

No geral, a ACREVI é composta por mulheres com faixa etária entre 45 e 65 anos e que, por razões diversas, buscam uma identidade profissional, conseguindo reintegrar-se ao trabalho por meios da atividade de coleta, separação e comercialização de matérias recicláveis. A coleta seletiva, uma atividade que muitas pessoas enxergam apenas lixo, essas mulheres veem oportunidades de trabalho e uma perspectiva de mudança na qualidade de vida e, muitas vezes, de superação da pobreza extrema. Nesse contexto, os trabalhadores e as trabalhadoras que se autoreconhecem como catadores (as) de material reciclável realizam um serviço de utilidade pública muito importante no contexto atual das cidades, atuando na coleta de materiais para reciclagem que, caso fossem descartados, ocupariam maior espaço em aterros sanitários e lixões e, portanto, a ação desses sujeitos contribuem para romper o ciclo de poluição do solo e da água (IPEA, 2013).

No Brasil, têm-se registros de que a maioria dos catadores se submete à condições degradantes, principiante devido às necessidades pela ausência de políticas de valorização ou reconhecimento desses profissionais pelo poder público local (GUIMARÃES, 2008; LEAL et al., 2002). Por outro lado, Medeiros e Macêdo (2006) acrescentam que essa atividade tem caráter muito lucrativo, mas, contraditoriamente, 
os catadores desempenham suas funções sob condições precárias, subumanas, e seus rendimentos individuais não Ihes asseguram sobrevivência digna.

Mesmo diante de tantas dificuldades, os catadores encontraram na coleta e na venda de materiais recicláveis um meio de obter renda, e ainda a melhor forma de destinação dos resíduos sólidos urbanos recicláveis. Entretanto, na maioria das vezes, as aspirações dos catadores de materiais recicláveis não são atingidas satisfatoriamente, pois não conseguem renda suficiente com essa atividade para as suas necessidades básicas, agravando os problemas sociais naturalmente vinculados a pessoas que atuam nesse segmento laboral, uma situação precária reflexo de uma sociedade historicamente embasada na lógica da exclusão e de desigualdade social. Muitas catadores e catadoras relatam trabalhar com o lixo por não terem tido outra opção de trabalho, pois a renda oriunda dessa atividade ajuda a melhorar as condições de habitação desses trabalhadores e de seus filhos (TEIXEIRA, 2015).

No contexto da ACREVI, a coleta seletiva materiais recicláveis e reutilizáveis é a fonte geradora de renda dos catadores que, embora considerada uma atividade comprovadamente lucrativa, os associados têm renda líquida mensal de $R \$ 300,00$ (trezentos reais), uma renda abaixo do limite da pobreza extrema (DIAS, 2020). Deste modo, conduziu-se uma pesquisa-ação com a finalidade de contribuir para aumentar a renda e a qualidade de vida dos associados, o que nos levou a investigar, em parceria com os associados da ACREVI, os principais problemas presentes na Associação, com vistas a identificar a necessidade de mudanças e contribuir com a transformação da realidade social dos associados.

\section{METODOLOGIA}

Esta pesquisa foi desenvolvida na Associação Comunitária Reciclando para a Vida (ACREVI), localizada no município de Mossoró-RN. A associação foi fundada em 1999. $\mathrm{Na}$ época, era composta por dez catadoras de materiais recicláveis, que realizavam as atividades de catação e separação com uso de carroça, exclusivamente no bairro Nova Vida.

A pesquisa foi direcionada metodologicamente pelos princípios da pesquisa-ação, uma vez que se buscava ações a fim de auxiliar a transformação da realidade social das catadoras a associação com a finalidade de transformar a realidade social das catadoras de matérias recicláveis e reutilizáveis (TRIPP, 2005; THIOLLENT, 1986).

$\mathrm{Na}$ fase exploratória identificou-se a necessidade de construir um galpão para a separação de materiais recicláveis com esteira e prensa. O uso da esteira de triagem facilita a separação dos materiais recicláveis pelos catadores e, o material reciclável, quando prensado e armazenado em um local protegido das intempéries (chuva e sol), mantém a qualidade, agregando valor ao preço de comercialização. Além disso, o galpão é um local de trabalho seguro e mantém o conforto térmico dos catadores da ACREVI, que trabalham embaixo de árvores ou em pleno sol.

Por outro lado, identificou-se que, sem opção de um local seguro e adequado para brincarem, os filhos dos catadores/recicladores da ACREVI convivem diariamente com o ambiente de trabalho insalubre dos seus pais. A partir deste contexto, desenvolveu-se um programa educacional para os filhos e netos dos catadores, incluindo atividades esportivas, brinquedoteca e atividades paralelas à escola relacionadas aos temas transversais (meio ambiente, saúde, segurança alimentar e nutricional). Essa ação teve a finalidade de desenvolver práticas educativas para mobilizar nas crianças da ACREVI atitudes de cuidado com o ambiente, a saúde e práticas de hábitos alimentares 
saudáveis, possibilitando às crianças a experiência, de valores, de atitudes diferentes daquelas que elas já conheciam. Nosso objetivo com essa ação foi ampliar o repertório delas sobre a realidade que viviam.

Além dessas questões, identificaram-se vários problemas de gestão e organização na ACREVI que também limitavam o seu desenvolvimento econômico e a maior renda das catadoras. Na associação, não há um modelo sustentável de gestão e organização financeira, além da ausência de metas de produção e mercados definidos de comercialização dos seus produtos. A falta de uma política adequada de relações públicas impede a consolidação de novos fornecedores/colaboradores de material reciclável e, consequentemente, a ampliação da quantidade de resíduos sólidos coletados. Assim, os catadores trabalham muito para separar os materiais recicláveis, obtendo reduzida renda por hora de trabalho, já que a maior parte dos materiais coletados é descartada para o lixão. Em busca de solucionar esses problemas, várias ações práticas foram desenvolvidas na ACREVI com o objetivo de melhorar a renda e a qualidade de vida dos associados por meio de práticas de gestão, organização, empreendedorismo e ações educativas.

O desenvolvimento e a descrição das ações da pesquisa, bem como os resultados e benefícios sociais são descritos a seguir.

\section{CONSTRUČ̃̃ DO GALPÃO DE TRIAGEM DE RESÍDUOS SÓLIDOS URBANOS RECICLÁVEIS}

Os catadores de materiais recicláveis passam a maior parte do seu tempo diário dentro das Associações e/ou Cooperativas para realizar suas atividades de coleta, separação e comercialização dos materiais oriundos da coleta seletiva local, mas, infelizmente, a maioria desses espaços não apresenta as condições mínimas de habitabilidade no que se refere a conforto e higiene, refletindo nas relações sociais e produtivas dos catadores.

Especificamente na Associação Comunitária Reciclando para a Vida (ACREVI), a inexistência de um galpão de triagem com as condições mínimas de habitabilidade forçava a realização dos catadores a céu aberto, submetendo-se a variações climáticas desfavoráveis e a um ambiente insalubre, com sérios riscos de contaminação.

A construção desse empreendimento foi viabilizada por um projeto orçamentário submetido e aprovado pelo Banco Santander e, este foi construído de estrutura metálica ocupando área de $120 \mathrm{~m}^{2}$ com as seguintes especificações: pilares metálicos com perfil U de 4" fixados com parafusos de $3 / 8$ " a $30 \mathrm{~cm}$ de profundidade, treliças metálicas confeccionadas em perfil U de 4", terças metálicas com perfis de 3" na chapa 14 enrijecida, cobertura executada em telha de zinco de $3 \mathrm{~mm}$, incluindo parafusos de fixação e calha executada em chapa de zinco (Figura 1). 
Figura 1 - Planta baixa do (A) e galpão construído e equipado com esteira (B), elevador e prensas de papelão, alumínio e garrafas PETs. (C)

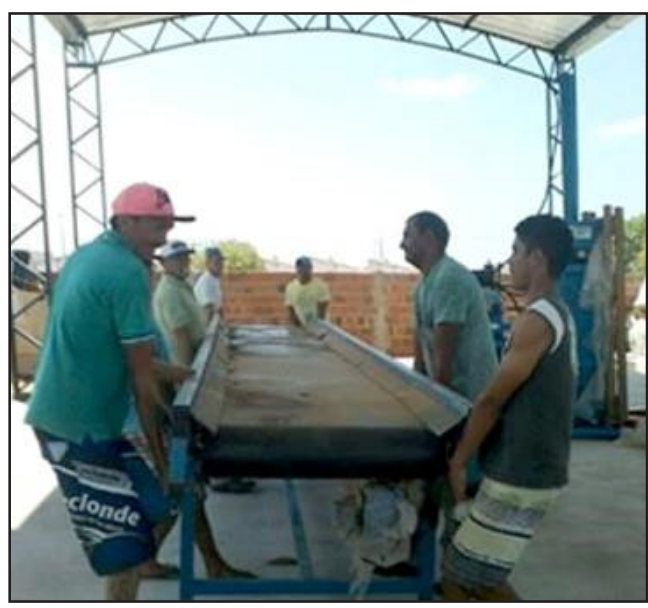

Fonte: Dados do acervo da pesquisa.

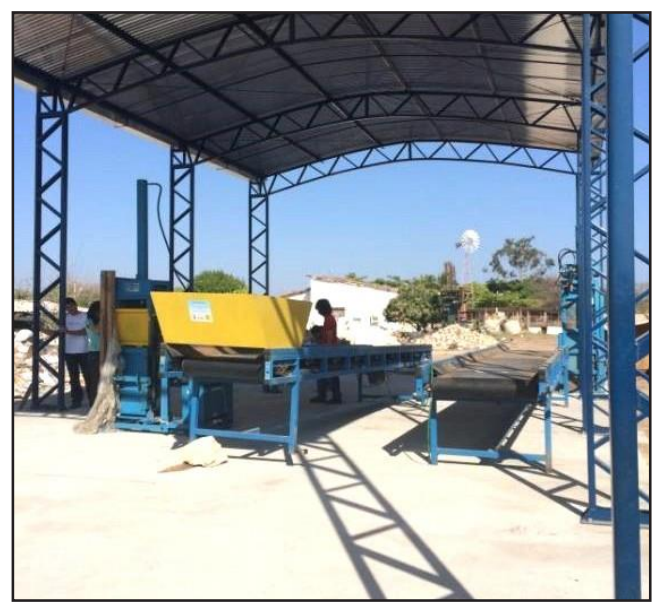

No projeto de construção do galpão, consideraram-se as características locais e a demanda dos catadores por um espaço amplo e com um teto alto, para onde pudessem alocar todos os equipamentos, inclusive o elevador de suspensão de fardos, conforme recomendação oficial (BRASIL, 2008), que define essa metodologia com base no fluxo dos materiais que serão processados. O elevador, a esteira e as prensas foram instalados de forma a contemplar o melhor layout do espaço de triagem, considerando desde a chegada até a prensagem dos materiais.

Após a construção do galpão e a acomodação dos equipamentos, realizou-se a instalação elétrica para o seu funcionamento e a iluminação. O galpão também servirá para o armazenamento e enfardamento do material reciclável prensado, justamente para manter a qualidade, evitando exposição à chuva e à insolação, especialmente do papel e do papelão.

Os resultados indicam que a construção do galpão e a instalação dos equipamentos para separação e prensagem do material reciclável proporcionou uma redução significativa no esforço físico dos catadores com relação ao trabalho de processamento dos materiais recicláveis oriundos da coleta seletiva realizada pela ACREVI. Este fato é visível quando os catadores retomam as suas atividades nas novas instalações, com as devidas adequações e a logística interna. Tal constatação reflete um maior rendimento em termos de produção de material reciclável processado por tempo trabalhado, menor acumulação de materiais e melhores condições ergométricas de trabalho, conforme atesta o relato de um catador:

Tudo ficou mais prático. O nosso trabalho diminui, a gente gastava muito tempo para amassar as latinhas de alumínio, mas hoje a prensa faz em poucos minutos o que lavávamos horas para fazer (informação verbal) ${ }^{5}$.

Além disso, a mudança da dinâmica de trabalho dos catadores resultou em melhorias das condições de trabalho, tornando-as mais seguras em termos de saúde, e também

\footnotetext{
${ }^{5}$ Relato de um reciclador da ACREVI.
} 
ampliou o espaço para o armazenamento adequado dos materiais já processados, protegendo-os de danos causados pela chuva e insolação, especialmente papelões e garrafas PET. Na Figura 2 têm-se os materiais recicláveis processados após a triagem oriunda da coleta seletiva.

Figura 2 - Papelão prensado e enfardada, conferindo a agregação do valor comercialdos materiais recicláveis.

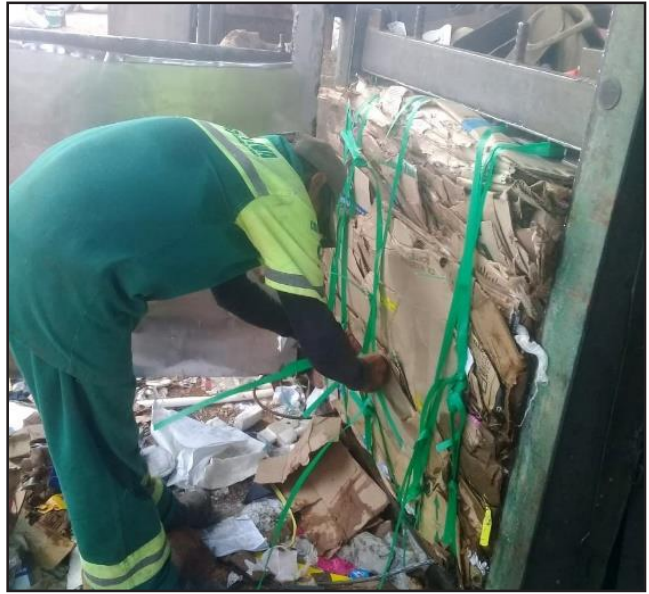

Fonte: Dados do acervo da pesquisa.

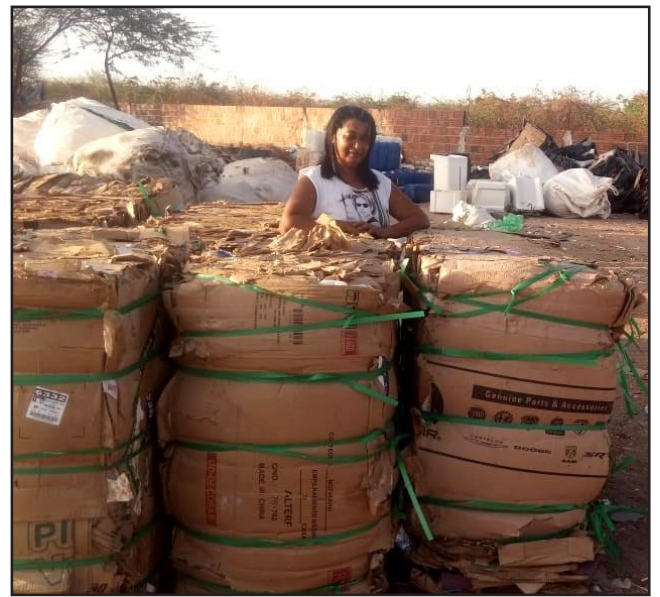

No que se refere aos preços de venda dos materiais recicláveis com o investimento galpão e equipamentos, pode-se contatar que o material processado rendeu aumentos significativos nos preços dos materiais recicláveis comercializados pela ACREVI, o que resultou na melhoria da renda dos catadores, uma vez que o material prensado confere a valorização na comercialização (Tabela 1).

Tabela 1 - Preço de venda de diferentes materiais recicláveis comercializados peloscatadores da ACREVI não prensados e prensados.

Preços dos materiais recicláveis $(\mathrm{R} \$$ por $\mathrm{Kg})$

\begin{tabular}{|c|c|c|c|c|}
\hline Condição & Papel branco & $\begin{array}{l}\text { Latinha de } \\
\text { alumínio* }\end{array}$ & Garrafa PET & Papelão \\
\hline $\begin{array}{l}\text { Prensado e/ou } \\
\text { enfardados }\end{array}$ & 0,16 & 3,00 & 1,30 & 0,34 \\
\hline $\begin{array}{c}\text { Não } \\
\text { prensado }\end{array}$ & 0,10 & 2,00 & 0,50 & 0,12 \\
\hline Aumento (\%) & 60 & 50 & 160 & 183,33 \\
\hline
\end{tabular}

"Latas de bebidas.

Fonte: Dados do acervo da pesquisa. 
Foi registrada uma valorização de $183 \%$ no valor de comercialização do papelão quando prensado, seguida da garrafa PET $(160 \%)$, papel branco $(60 \%)$ e latinha de alumínio (50\%). Pode-se inferir que esta ação foi um dos mecanismos-chave para a melhoria de renda, qualidade de trabalho e eficiência nas atividades de coleta seletiva realizada pela ACREVI.

É importante destacar a valorização comercial da latinha de alumínio em relação aos demais materiais recicláveis. Enquanto elas chegam a custar $R \$ 3,00 \circ \mathrm{kg}$, a garrafa $P E T$, segundo material de maior valor, rende no máximo $R \$ 1,30$ por $\mathrm{kg}$.

A construção de um galpão de triagem foi uma das principais aspirações dos catadores devido à praticidade de armazenamento dos materiais recicláveis, à valorização comercial, à praticidade na execução das atividades na associação etc. De acordo com Brasil (2008), a venda dos materiais em maior volume é bastante vantajosa. Portanto, o espaço de estocagem deve permitir a melhor condição de comercialização de acordo com a realidade local.

Embora os catadores exerçam suas atividades sob condições adversas, em que a atividade laboral, em todas as suas fases, exige muito esforço, ainda assim eles acreditam na importância e na viabilidade do trabalho associativo e prezam pela organização do galpão onde são estocados os materiais coletados para comercialização.

A conquista desse espaço para a estocagem de materiais e para a instalação dos equipamentos foi fundamental para a funcionalidade do trabalho associativo, pois as tarefas e o tempo dos catadores foram otimizados com a ajuda das máquinas e do seu layout, ou seja, devido à forma como esses instrumentos estavam dispostos no galpão.

Com o galpão em funcionamento, os materiais recicláveis oriundos da coleta seletiva da ACREVI passaram a ser estocados de forma segura e livre das intempéries, que os faziam perder valor de mercado. Por conta disso, materiais como papel, papelão, alumínio e PET mantiveram as suas características originais. Seus preços de comercialização foram valorizados e, consequentemente, a renda dos catadores também sofreu uma variação positiva.

\section{DIÁLOGO SOBRE EDUCAÇÃO AMBIENTAL, SAÚDE E BEM-ESTAR COM FILHOS E NETOS DOS CATADORES}

Nesta ação, desenvolveu-se práticas que mobilizaram atitudes de cuidado e formação dos filhos e netos dos catadores da ACREVI, a fim de que esses pudessem refletir sobre a vida e a relação deles com o meio em que vivem.

As ações educacionais do projeto incluem a construção física de um espaço lúdico para as crianças e que, ao mesmo tempo, ofereça atividades paralelas à escola relacionadas aos temas transversais (meio ambiente, saúde, ética, datas comemorativas, segurança alimentar etc.), esportivas e culturais, aproximando as crianças das produções artísticas e conscientizadoras de seus direitos (BRASIL, 1998).

As atividades do projeto direcionadas para ações educativas foram desenvolvidas, semanalmente, com as 20 crianças da Associação, durante o período de março de 2015 a março de 2016. A metodologia realizada privilegiou o desenvolvimento de outros conhecimentos, a elaboração/reelaboração de ideias e conceitos, bem como a partilha de aprendizagem ocorridas por meio da pesquisa. Baseou-se na elaboração de ferramentas pedagógicas para um programa de atividades de intervenção nutricional específico direcionado às crianças da $\mathrm{ACREVI}$, quais sejam: construção coletiva de uma brinquedoteca com materiais recicláveis, oficinas semanais abordando temas diversos 
como pintura, saúde bocal, educação ambiental, segurança alimentar e nutricional e atividades esportivas (prática de capoeira).

\subsection{Construção da brinquedoteca com materiais reutilizáveis da coleta seletiva}

Este espaço foi montado em uma sala na associação com o intuito de oferecer às crianças da ACREVI um local aonde pudesse ser realizadas as atividades recreativas e educativas (brincadeiras, leituras, filmes, TV, jogos etc.) e ainda para diálogos sobre temas transversais como meio ambiente (água, ar e lixo), ética, saúde e segurança alimentar e nutricional. Além disso, a brinquedoteca é um local reservado e adequado para as crianças, no qual podem-se concentrar nas atividade propostas, enquanto seus pais trabalham.

A brinquedoteca foi organizada em uma sala dentro da ACREVI com $14 \mathrm{~m}^{2}$. Em geral, priorizou-se a confecção de brinquedos e acessórios utilizando materiais recicláveis como pneus usados (Puff e expositores de pelúcia), garrafas PET e potes de sorvete (carros e porta lápis de cor etc.). A brinquedoteca foi preparada para receber um espaço do "faz-de-conta" a fim de mobilizar a criatividade, as manifestações de afeto e de apreciação pela cultura infantil, a tal ponto que a criança se sentisse pertencente a um ambiente acolhedor.

A ideia principal da brinquedoteca é valorizar a relação das crianças com o lúdico, por meio dos brinquedos, de atividades educativas que fazem parte do universo infantil, além de possibilitar o desenvolvimento global das crianças a partir de práticas pedagógicas que, inclusive, possibilitem a aproximação entre as gerações (Figura 3).

Figura 3 - Brinquedoteca: um espação de recreação e leitura construído para as criançasda ACREVI.
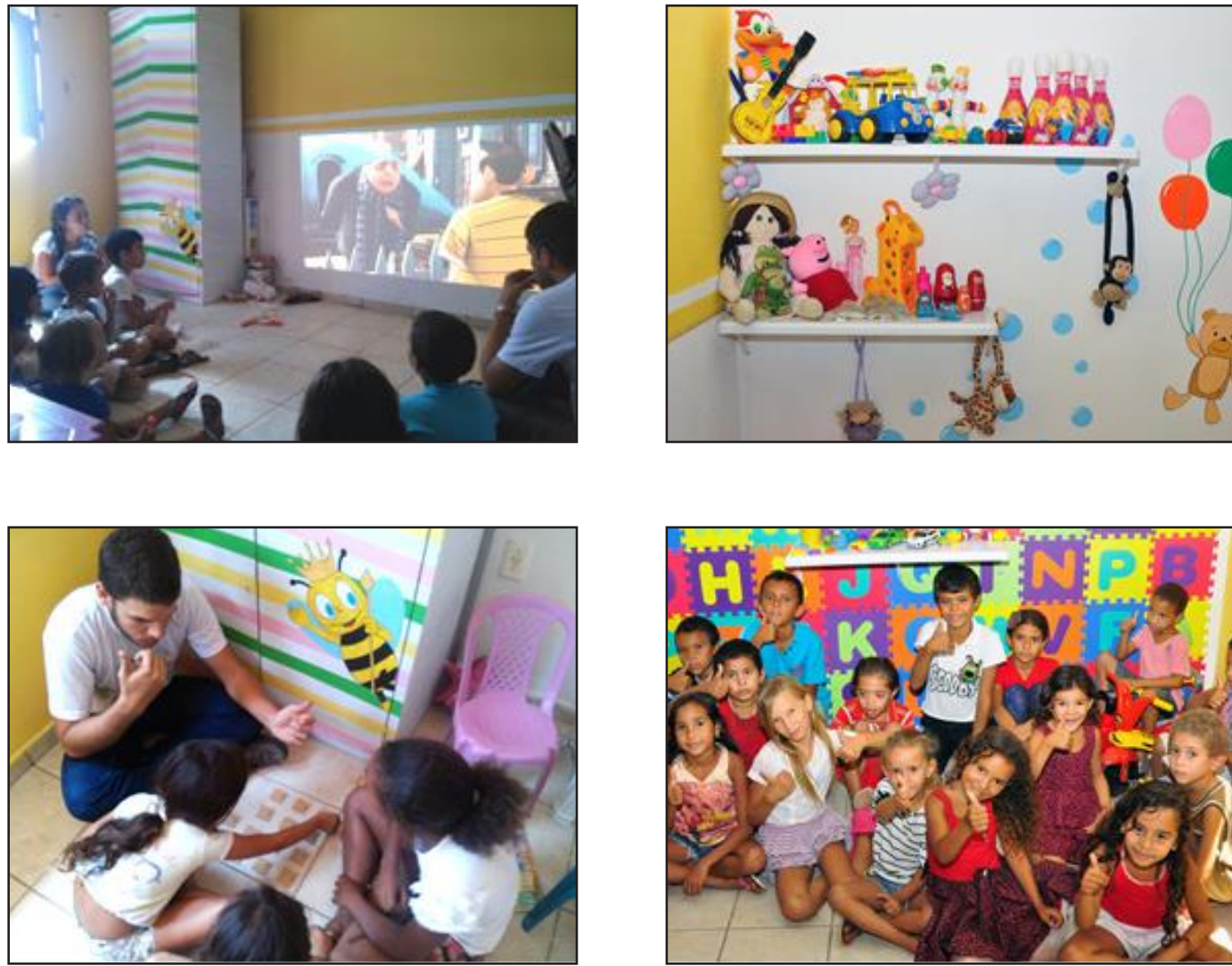

Fonte: Dados do acervo da pesquisa. 


\subsection{Oficinas de educação ambiental}

Nesta ação, foram realizadas semanalmente várias oficinas sobre educação ambiental com as crianças da ACREVI. As oficinas ocorreram sempre nas manhãs dos sábados, por ser o dia da semana em que todas as crianças estavam presentes na associação, garantido uma maior participação.

$\mathrm{Na}$ primeira etapa das oficinas foram trabalhados os temas transversais: meio ambiente e separação de materiais recicláveis (Figura 4), utilização de materiais recicláveis e reutilizáveis (Figura 5), uso consciente da água (Figura 6), atividades vinculadas ao trabalho dos seus responsáveis.

Figura 4 - Oficina sobre a importância ambiental e desenhos elaborados pelas crianças sobre o trabalho realizado por seus responsáveis na ACREVI.

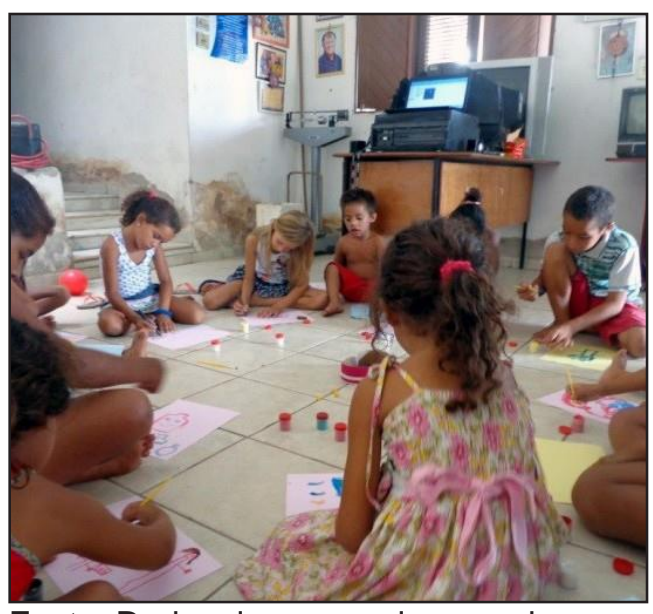

Fonte: Dados do acervo da pesquisa.

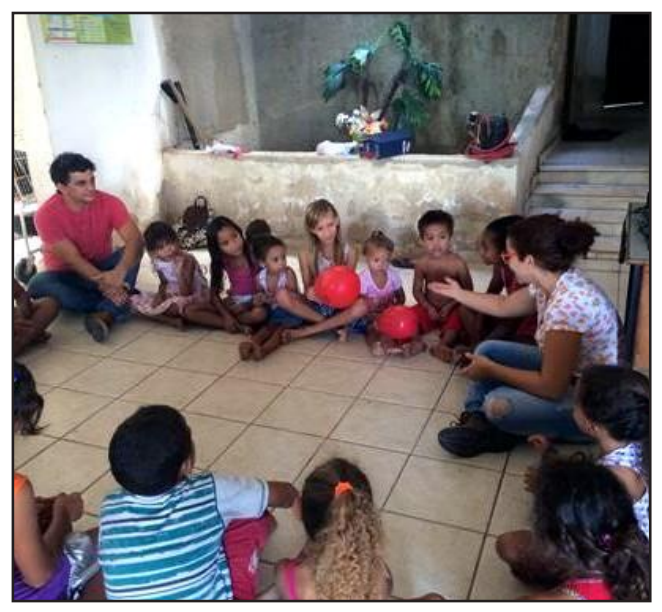

Figura 5 - Oficina de arte com as garrafas PETs aliadas ao trabalho de horta orgânica.

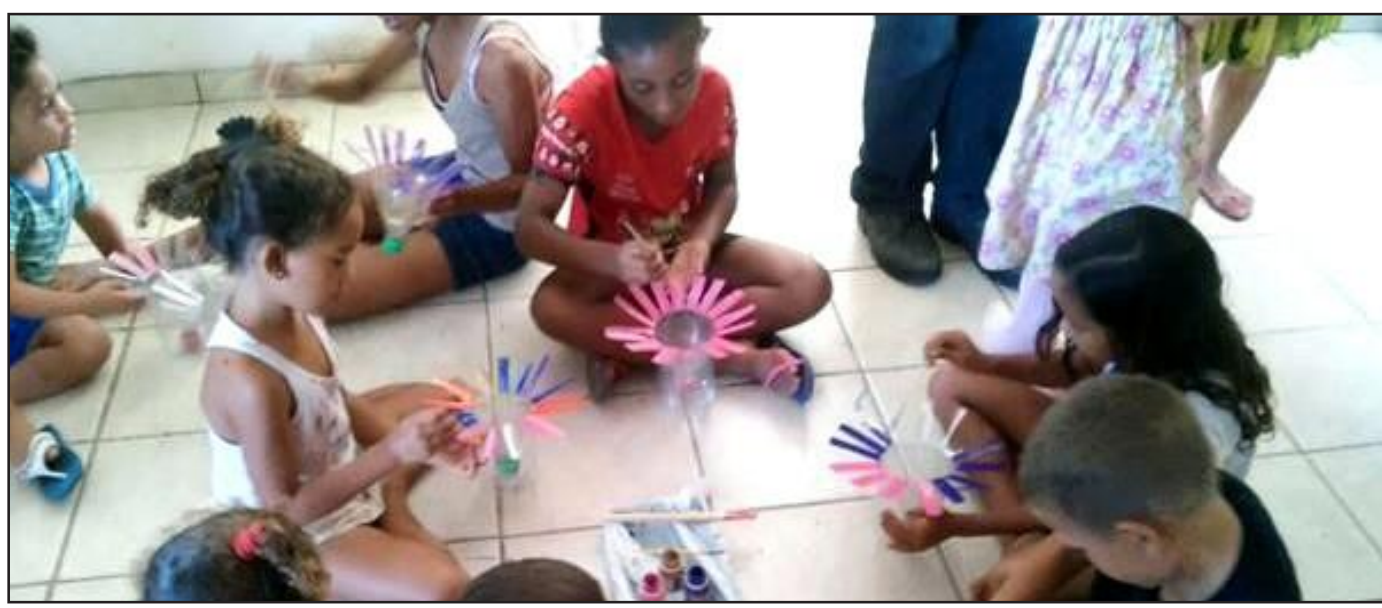

Fonte: Dados do acervo da pesquisa. 
Figuras 6 - Oficina sobre uso consciente da água e cartaz produzido sobre a temática.
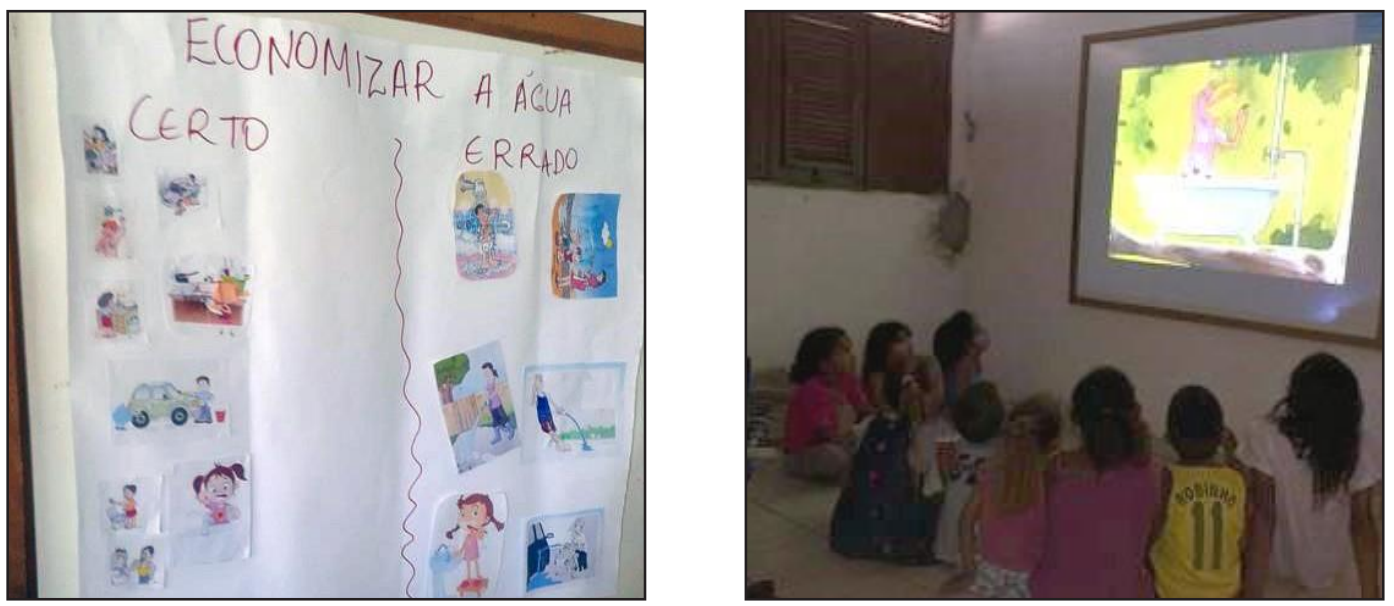

Fonte: Dados do acervo da pesquisa.

É importante que o trabalho de sensibilização e educação ambiental seja realizada inicialmente com as crianças, pois, essas, além de ensinarem aos adultos o que aprenderam, elas também crescem conscientes de que ações realizadas em seu cotidiano podem contribuir para amenizar o grave problema de um mundo consumista. Assim, ao assumirem novos comportamentos e mudanças de atitudes, contribuem para a formação de um mundo melhor.

Outro aspecto relevante dessas oficinas foi o fortalecimento da identidade das crianças, pois, acredita-se que o ato de desenharem o trabalho de seus responsáveis gerou o sentimento de valorização do grupo social a qual elas pertencem.

$\mathrm{Na}$ segunda etapa das oficinas, teve-se como objetivo o protagonismo e a autonomia das crianças da ACREVI a partir de atividades lúdicas que promovessem a higienização bucal (Figura 7). Além disso, foi realizada uma oficina sobre as práticas e hábitos alimentares saudáveis e a importância de alimentar-se bem. Especificamente, foram abordados e discutidos temas como os bons hábitos alimentares, as vitaminas dos alimentos, os principais alimentos e seus benefícios para nossa saúde, a importância de uma alimentação equilibrada, as consequências da alimentação não saudável, a necessidade de se alimentar de legumes, verduras e frutas como opção de saúde, o desperdício de alimentos e, principalmente, como estes podem ser aproveitados como os alimentos podem ser aproveitados antes de serem destinados ao lixo, além dos cuidados com a higiene alimentar e seus benefícios (Figura 8). 
Figura 7 - Uso do macro modelo de escovação gigante com língua para explicar as etapas de higienização bucal de forma divertida na oficina.

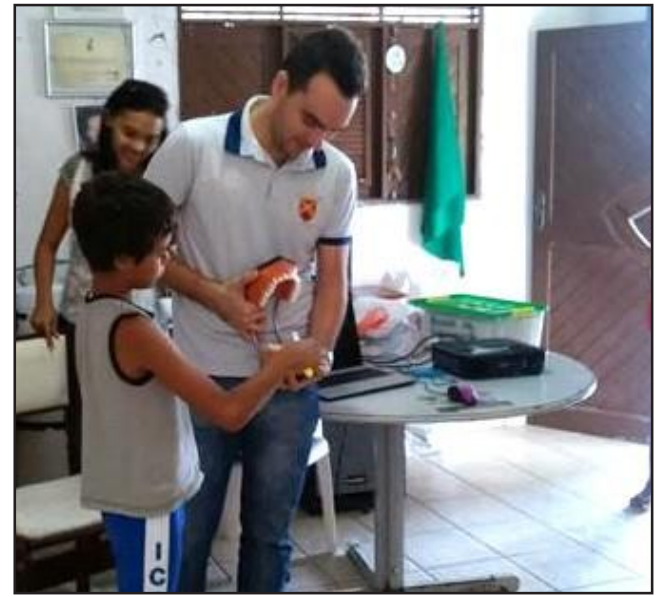

Fonte: Dados do acervo da pesquisa.

Figura 8 - Dinâmica da caixa dos sentidos realizada com as crianças da ACREVI.

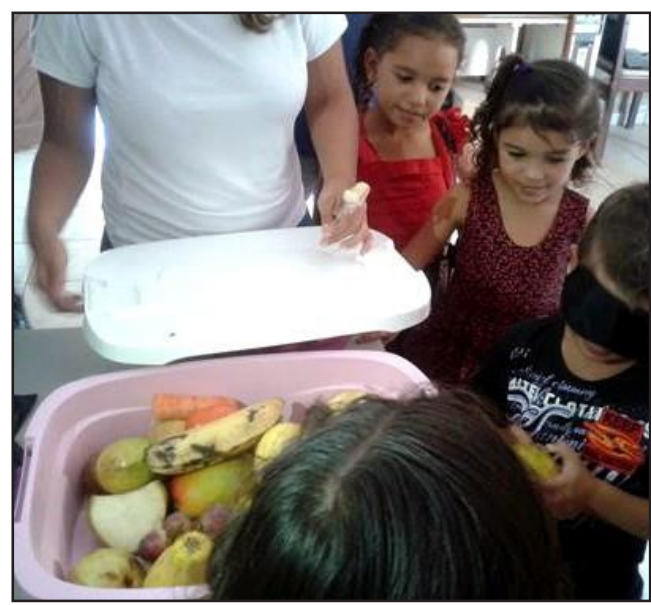

Fonte: Dados do acervo da pesquisa.

Como incentivo para as crianças praticarem uma atividade esportiva, iniciaram-se, na ACREVI, aulas de capoeira visando ao desenvolvimento de habilidades individuais e à coletividade. Isto não se deu de maneira obrigatória nem sequer em caráter competitivo, pois o objetivo era vivenciar algo prazeroso. As aulas de capoeira são realizadas semanalmente, com duração de uma hora, mantendo-se uma rotina na vida das crianças, de modo a estimular o espírito de grupo, o respeito ao próximo e a disciplina (Figura 9). 
Figuras 9 - Aulas semanais de capoeira e primeira apresentação da atividade comum grupo de capoeira.

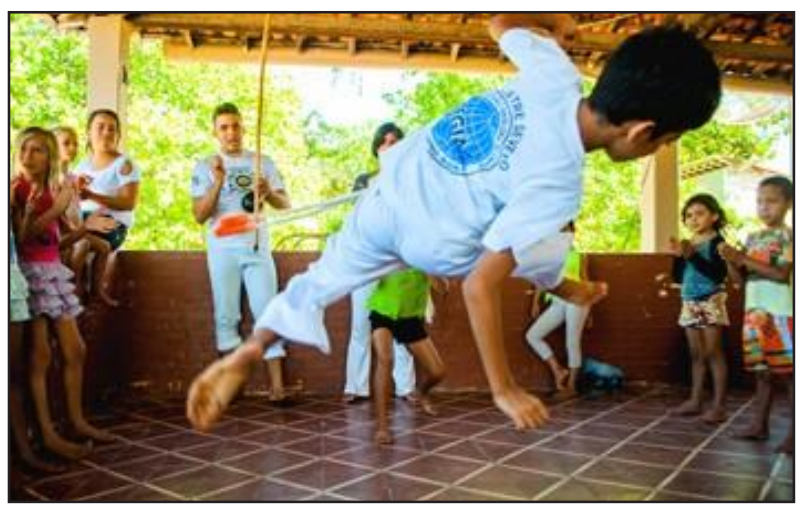

Fonte: Dados do acervo da pesquisa.

Após um ano de atividade, com o desenvolvimento e o aperfeiçoamento nos treinos, as crianças puderam interagir com outros grupos de capoeira do município de Mossoró (RN) e ainda tiveram participação em diversos eventos de capoeira fora da ACREVI.

A capoeira foi escolhida por ser expressão da cultura popular e da ancestralidade afro-brasileira e, possibilita aos seus participantes experiência as artes marciais, o canto, os instrumentos musicais, a dança, o lazer, a filosofia de vida. Esse universo de possibilidades permiti à criança ter contato com várias linguagens e atuar naquela ou naquelas que mais se identificar. Assim, a capoeira auxilia na formação integral dos participantes, seja nos aspectos cognitivos, afetivos e nos psicomotores.

Outra ação desenvolvida foi o teatro de fantoches, utilizado também como instrumento de avaliação de ensino-aprendizagem das crianças. Foram criados os personagens João e Maria para interagirem com as crianças e verificar a opinião delas sobre as práticas educativas realizadas, em que tal ação sempre ocorria uma semana após das outras atividades acontecerem (Figura 10).

Figura 10 - Apresentações de teatro de fantoches para revisar e avaliar as atividadescom as crianças.

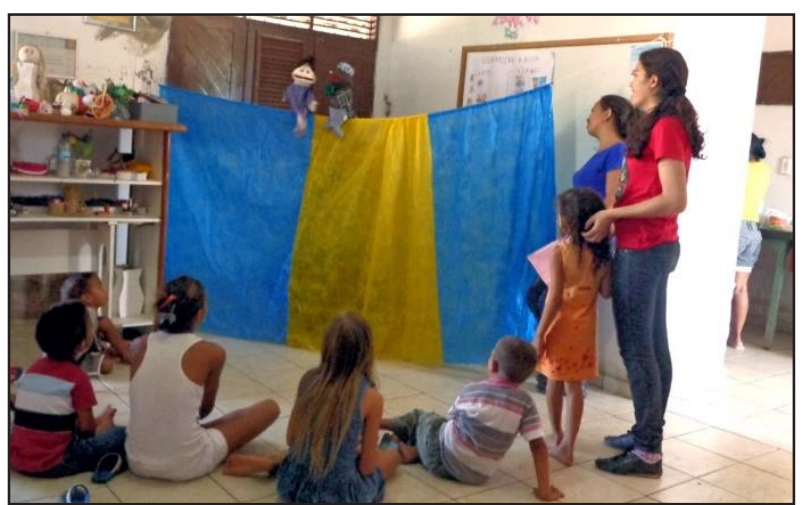

Fonte: Dados do acervo da pesquisa. 
No teatro de fantoches, os personagens João e Maria indagavam às crianças de uma forma divertida e lúdica sobre as atividades que teriam ocorrido na semana anterior, e o que elas haviam aprendido, por exemplo, sobre o uso consciente da água e/ou sobre a saúde bucal.

\section{AÇÕES DE APRENDIZAGEM, FORMAÇÃO E DE NATUREZA ORGANIZACIONAL}

Além das ações educativas direcionadas para as crianças, foram realizadas atividades de formação de autogestão e empreendedorismo para os associados da ACREVI, seja na atividade da coleta seletiva ou correlatas. Nesse contexto, desenvolve-se várias ações empreendedoras na ACREVI com a inovação de produtos, serviços e ideias e, também, com a formação profissional dos catadores na perspectiva de aperfeiçoamento das atividades existentes e/ou inovadoras correlacionadas à coleta seletiva.

\subsection{Troca de experiência}

Foi promovida trocas de experiências entre a ACREVI e a Associação de Criadores de Camarão de Icapuí-CE (ACCl) como ação adquirida por formação que, de acordo com Andrade, Lima e Borges (2014), é uma atividade empreendedora formal internalizada utilizando formações continuadas através de intercâmbios, cursos, palestras, oficinas de formação e leitura. Nesta troca de experiência, os (as) catadores (as) conheceram um modelo de gestão de associação que passou por várias dificuldades e, atualmente tem um plano de gestão consolidado e bem administrado. $O$ modelo relatado pelo presidente da ACCl pode servir de inspiração para a construção do modelo de gestão na ACREVI (Figura 11).

Figura 11 - Registro do encontro entre a ACREVI e a ACCI.
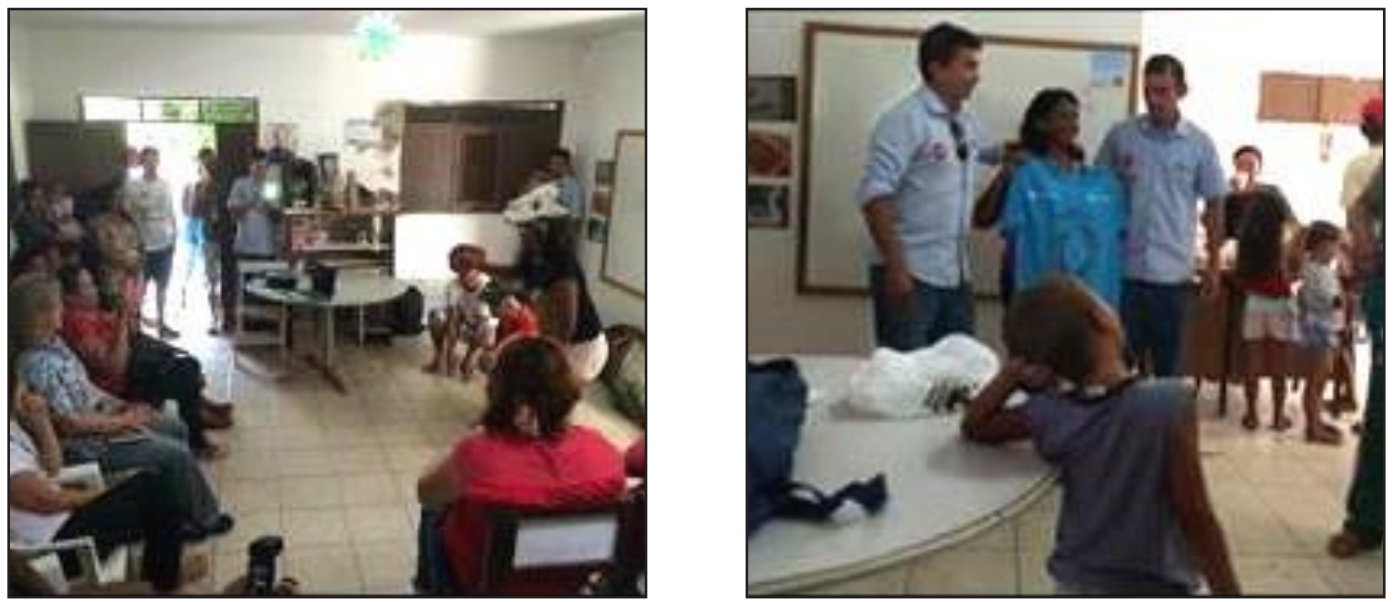

Fonte: Dados do acervo da pesquisa.

As trocas de entre grupos de diferentes realidades são importantes para a construção da aprendizagem, pois esta ocorre fundamentalmente nas relações sociais entre os indivíduos engajados numa prática, os quais intercambiam experiências, conhecimentos e significados (ÖRTENBLAD, 2001; SOUZA-SILVA; SCHOMMER, 2008). 


\subsection{Oficina de formação sobre segurança no trabalho}

Por se tratar de uma atividade de alto risco de acidentes no trabalho, foi realizada uma oficina sobre segurança no trabalho, a fim de garantir que os catadores tenham noções básicas sobre o uso de EPIs e os riscos diários de acidentes e suas medidas preventivas. De maneira dialogada, apresentaram-se os riscos físicos, químicos, ergonômicos e mecânicos ou de acidentes a que os (as) catadores (as) estãoexpostos (as) diariamente, além dos riscos biológicos envolvidos na atividade. Em seguida, foram apresentados os equipamentos indispensáveis ao local de trabalho mais seguro (luvas, máscaras, botas, protetores auriculares e roupas apropriadas), além da abordagem sobre a importância da separação dos materiais recicláveis para a sustentabilidade (Figura 12).

Figura 12 - Oficina sobre segurança no trabalho na coleta e separação dos resíduos sólidos.

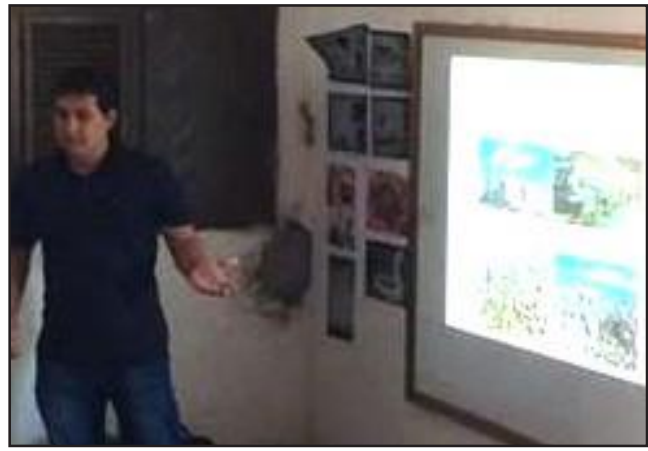

Fonte: Dados do acervo da pesquisa.

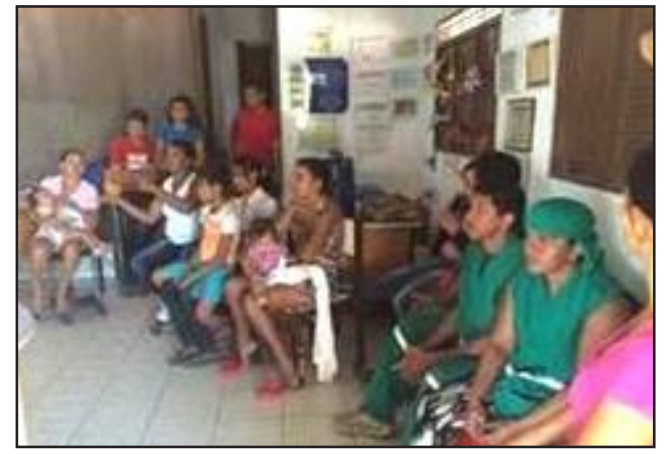

\subsection{Curso de noções básicas de informática}

Tendo em vista o pouco contato com a informática e as necessidades de comunicação digital com outras associações, realizou-se um curso de formação para os catadores da ACREVI sobre noções básicas de informática (ligar e desligar o computador, componentes do computador, como usar o Word e como acessar as redes sociais e sites de busca). No curso, também foram ofertados exemplos de elaboração de ofícios e relatórios (Figura 13).

Figura 13 - Curso de informática básica realizado na ACREVI.

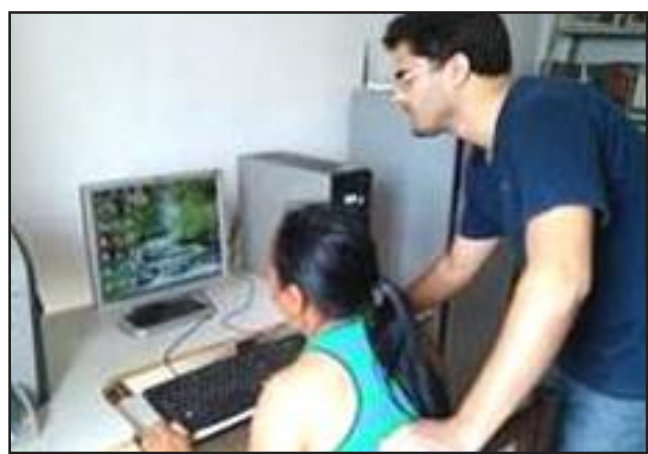

Fonte: Dados do acervo da pesquisa.

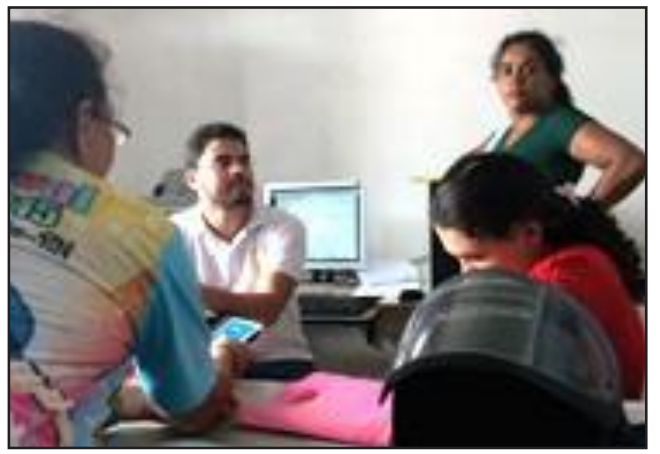




\subsection{Oficina de aproveitamento de materiais recicláveis}

Esta oficina foi ofertada aos (às) associados (as) da ACREVI com o objetivo de despertar o interesse e a criatividade de fabricar objetivos diversos utilizando materiais recicláveis, principalmente garrafas $\mathrm{PET}$, papelão e lata de alumínio. A oficina também teve um caráter educativo, em que se aplicaram alguns dos conceitos dos 5 R's (repensar, reduzir, reutilizar, reciclar e recusar), uma vez que se trabalhou com os materiais que seriam descartados após seu uso inicial como materiais para a produção de novos objetos utilitários, podendo inclusive ser comercializados (Figura 14).

Figura 14 - Oficina de aproveitamento de matérias recicláveis na ACREVI.
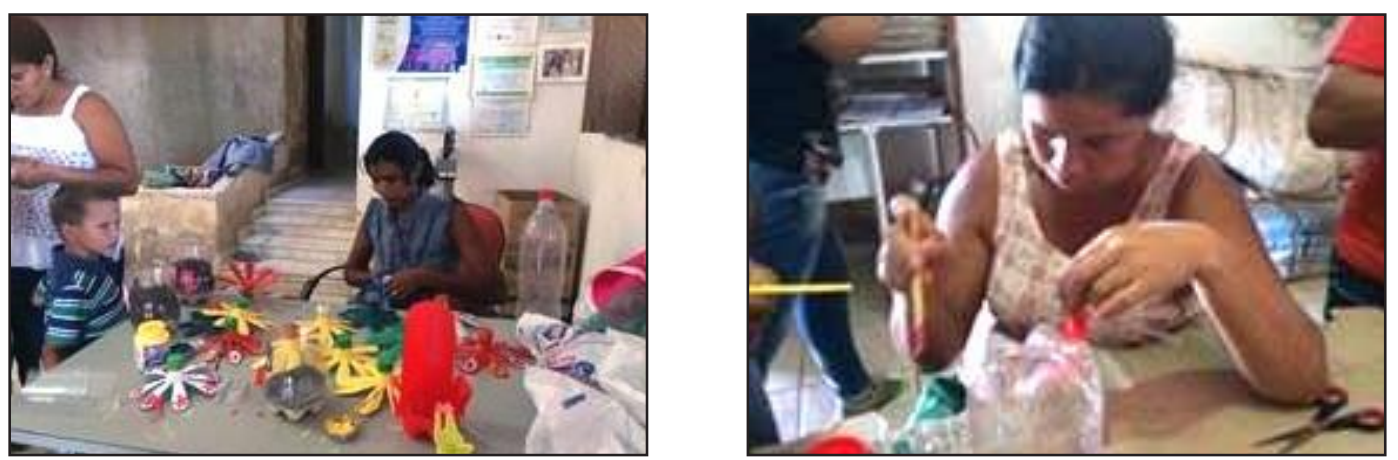

Fonte: Dados do acervo da pesquisa.

\subsection{Divulgação da ACREVI nas redes sociais}

Foram criadas contas no Facebook e Instagram, campanhas educativas e principalmente para receber doações voluntárias, divulgação e vendas de produtos personalizados com a logomarca criados pelos próprios associados (Figura 15).

Figura 15 - Divulgação da ACREVI no Instagram e Facebook.
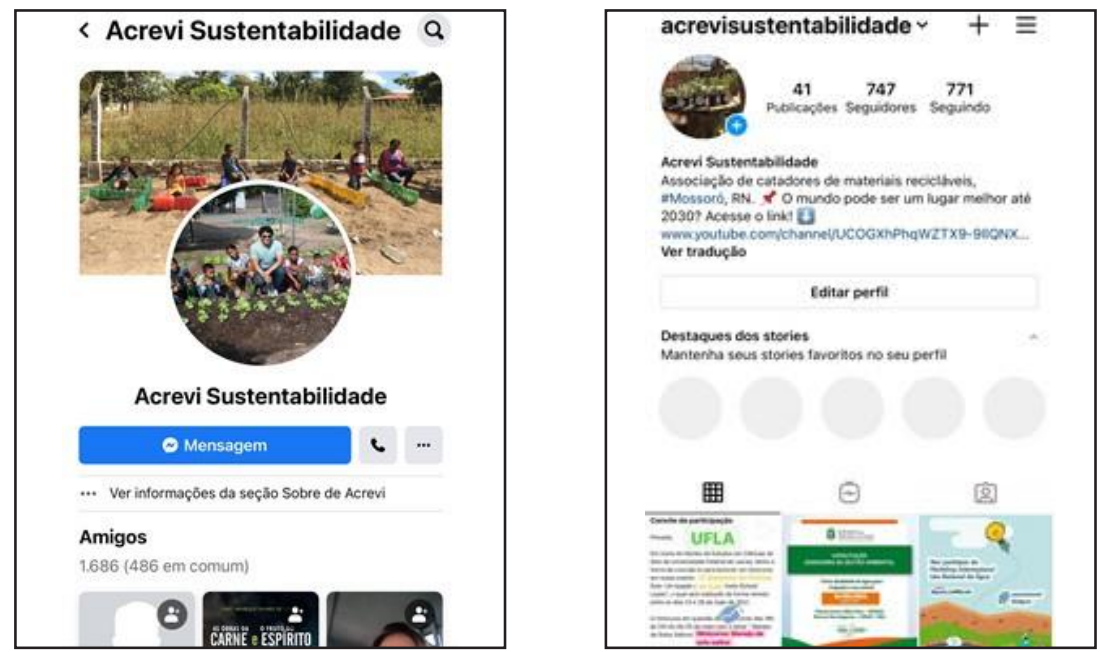

Fonte: Dados do acervo da pesquisa. 
As redes sociais não foram utilizadas apenas como um espaço interativo e educativo, mas também para firmar novas parcerias, especialmente para interagir com voluntários que oferecem vários tipos de matérias recicláveis, como livros, folhas de papel etc.

\section{CONSIDERAÇÕES FINAIS}

$\mathrm{Na}$ pesquisa-ação é importante desenvolver ações de autogestão do projeto trabalhado justamente para que a comunidade continue com as atividades ou implemente novas ações de transformação, beneficiando a comunidade.

A construção e o funcionamento do galpão de triagem melhoraram as atividades da coleta seletiva em vários aspectos como qualidade e segurança do trabalho, melhor qualidade comercial dos materiais recicláveis $e$, consequentemente, aumentou a renda mensal dos catadores e catadoras da ACREVI.

As ações sobre educação ambiental, segurança alimentar e nutricional e o uso da brinquedoteca são sementes plantadas, principalmente, entre as crianças, que contribuíram para a sensibilização e formação de sujeitos responsáveis pela transformação de sua realidade social.

Os cursos de formação sobre empreendedorismo despertaram nos associados o interesse na inovação e aprendizagem coletiva, o que posteriormente pode criar oportunidades lucrativas para a ACREVI.

O maior desafio dessa pesquisa foi a tentativa constante de envolvimento de alguns catadores no projeto, sendo este dificultado pelo ciclo rotineiro de saída e entrada de novos associados, dificultando a participação deles em algumas decisões.

\section{REFERÊNCIAS}

ANDRADE, D. M.; LIMA, J. B.; BORGES, A. F. Ações Empreendedoras em Empresas Familiares: Um Estudo Sob a Ótica de Oportunidades, Inovação e Aprendizagem. In: ENCONTRO DE ESTUDOS EM EMPREENDEDORISMO E GESTÃO DE PEQUENAS EMPRESAS, 8., 2014, Goiânia. Anais... Goiânia: UFG. 1 CD-ROM.

BRASIL. Elementos para a organização da coleta seletiva e projeto dos galpões de triagem. Brasília: Ministério do Meio Ambiente, 2008. Disponível em: https://www. mma.gov.br/estruturas/sqa pnla/ arquivos/manual coleta seletiva correto 46.pdf.

Acesso em: 23 mar. 2020.

BRASIL. Lei n. 9605/98, de 12 de fevereiro de 1998. Dispõe sobre as sanções penais e administrativas derivadas de condutas e atividades lesivas ao meio ambiente, e dá outras providências. Brasília: Presidência da República; Casa Civil, 1998. Disponível em: http://www.planalto.gov.br/ccivil 03/Leis/L9605.htm. Acesso em: 11 jun. 2018.

BRASIL. Instituto de Pesquisa Econômica Aplicada. Secretaria de Assuntos Estratégicos da Presidência da República. Situação Social das Catadoras e dos Catadores de Material Reciclável e Reutilizável. Brasília: IPEA, 2013. Disponível em: http://www. ipea.gov.br/portal/images/stories/PDFs/situacao social/131219 relatorio situacaosocial mat reciclavel brasil.pdf. Acesso em: 11 mai. 2017. 
DIAS, N. F. Pesquisa-Ação: troca de saberes acadêmicos e popular. 2020. Disponível em: $\quad$ https://nossaciencia.com.br/colunas/pesquisa-acao-troca-de-saberesacademicos-\%20e-popular/. Acesso em: 02 dez. 2020.

GUIMARÃES, Mauro. Educação Ambiental Crítica. Ministério do Meio Ambiente (Org.). A Educação Ambiental no Brasil. Brasília: MMA, 2008.

LEAL, Antonio C.; T. JÚNIOR, Antonio; ALVES, Neri.; GONÇALVES, Marcelino A.; DIBIEZO, Eduardo P. A reinserção do lixo na sociedade do capital: uma contribuição ao entendimento do trabalho na catação e na reciclagem. Revista Terra Livre, São Paulo, v. 18, n. 19, p. 177-190, 2002.

MEDEIROS, Luiza F. R.; MACÊDO, Kátia B. Catador de material reciclável: uma profissão para além da sobrevivência? Psicologia \& Sociedade, v. 18, n. 2, p. 62-71, 2006.

ÖRTENBLAD, A. On differences between organizational learning and learning organization. The learning organization, v. 8, n. 3, p. 125-133, 2001.

SOUZA-SILVA, J. C.; SCHOMMER, P. C. A pesquisa em comunidades de prática: panorama atual e perspectivas futuras. Organizações e Sociedade, v. 15, n. 4, jan./ mar. 2008.

TEIXEIRA, Karla M. D. Trabalho e perspectivas na percepção dos catadores de materiais recicláveis. Psicologia \& Sociedade, v. 27, n.1, p. 98-105, jan./abr. 2015.

THIOLLENT, Michel. Metodologia da pesquisa-ação. São Paulo: Cortez; Autores Associados, 1986.

TRIPP, David. Action research: a methodological introduction. Educação e Pesquisa, São Paulo, v. 31, n. 3, p. 443-466, dez. 2005. Disponível em: http://www.scielo.br/scielo. php?pid=S1517-97022005000300009\&script=sci abstract. Acesso em: 06 mar. 2020. 